\title{
Egg donation compensation: ethical and legal challenges
}

This article was published in the following Dove Press journal:

Medicolegal and Bioethics

26 September 2014

Number of times this article has been viewed

\author{
Nancy J Kenney' \\ Michelle L McGowan² \\ 'Departments of Psychology and \\ Gender, Women, and Sexuality Studies, \\ University of Washington, Seattle, \\ WA, USA; ${ }^{2}$ Department of Bioethics, \\ Case Western Reserve University, \\ Cleveland, $\mathrm{OH}$, USA
}

\begin{abstract}
Nearly 8,000 children were born in the US in 2011 as a result of assisted reproductive technology involving the use of donor oocytes. While this technology has been widely utilized, worldwide numbers are difficult to calculate. The ethics of the process and of payment provided to donors continue to be highly debated. This paper examines international debates about the legality and morality of the use of donor eggs to assist in family development and just recompense of donors. Aside from a nearly universal perspective that oocytes should not be purchased and sold as commodities, no consensus has been reached on appropriate recompense for egg donors. Major issues in this debate include the relative acceptability of monetary payment versus payment in the form of reduced fees for other reproductive services (often as a result of egg or sperm sharing) and the factors to be considered in determining the just compensation for the time, pain, discomfort, and potential physical risk egg donors face in this process. The effects of legal interventions imposed in various national contexts on the availability of this technology, the influence of egg cryopreservation, and the use of donated eggs for research rather than reproduction are discussed. The effects of US reliance on professional organizational guidelines to oversee donor compensation are addressed, including assessment of their effectiveness in preventing differential rewards for eggs of donors who share characteristics that are highly prized such as beauty, athleticism, and intellectual giftedness. Currently, there is little long-term monitoring of the physical and psychological aftereffects of oocyte donation. Lack of understanding of these effects makes determination of a just payment for egg donation challenging.
\end{abstract}

Keywords: compensation, ethics, law, assisted reproductive technology, recompense

\section{Introduction}

The use of donor eggs in assisted reproductive technology (ART) has increased rapidly since the first birth following the use of this technology to a woman experiencing primary ovarian failure in $1983 .{ }^{1}$ In 2011 (the most recent year for which statistics are available), 18,530 ART cycles in the US involved the use of donor eggs. ${ }^{2}$ That represents $13.9 \%$ of all ART cycles, up from approximately $8 \%$ in 1995 , the first year such data were collected. ${ }^{3}$ In 2011, 7,902 live births resulted from the use of donor eggs. National statistics do not indicate either the number of donors or the number of recipients involved in the process. Equivalent global statistics are difficult to compile due to variable mechanisms for tracking and presenting oocyte donation practices across jurisdictions.

While the benefits of oocyte donation in assisting reproduction of women who are unable to produce eggs are clear, many aspects of oocyte procurement and use remain controversial. Indeed, with the introduction of egg donation for research and
Correspondence: Nancy J Kenney University of Washington, Department of Psychology, Box 351525,

Seattle, WA, 98195, USA

$\mathrm{Tel}+\mathrm{I} 2065432563$

Fax+I 2066853157

Email nkenney@uw.edu 
cryopreservation of eggs, the controversies are increasing. This paper will focus specifically on the controversies surrounding the legality and morality of various forms of payment for egg donation, including direct reimbursement for financial expenses incurred by participating in donation, compensation for time, discomfort, and inconvenience, reward for participating in donation that goes beyond compensation, and purchase of eggs. ${ }^{4}$ Specifically, we will address how many nation states have invoked ethical doctrine and developed regulatory structures as they grapple with the issue of adequate and just recompense of donors. We will also examine the debate that has focused on whether any payment for the provision of oocytes inappropriately commodifies the seeds of human life and treats women as means to ends. ${ }^{5,6}$ We will argue that lack of clear understanding of the long-term consequences of egg donation on the physical and psychological well-being of egg donors makes determination of a fair level and form of payment for donors difficult.

\section{Legality of egg donation}

On an international scale, most nation states that have laws regarding oocyte donation have made financial remuneration of egg donors illegal, on the basis that monetary reward runs the risk of exploiting donors and commodifying their eggs and resulting offspring. ${ }^{7}$ Some national restrictions on reproductive technology derive from the nation's strong religious identity and the moral-ethical positions resulting from the religious base. Costa Rica, based on its Catholic identification, currently is among the most restrictive counties for all ART. Italy, also related to Catholic perspectives, bans reproduction using sperm and oocyte donation. Muslim countries governed by Sunni authorities also ban gamete donation while those that are Shia-dominant are less restrictive. Turkey, a Sunni-dominant Muslim country, not only bans gamete donation and surrogacy within its borders but also bans its citizens from accessing such fertility treatments in other countries. $^{8}$

Not all national bans on reproduction using donated oocytes are based in religious beliefs. Germany's Embryo Protection Act of 1990 forbids practitioners from participating in the origination of a pregnancy from an egg cell produced by another woman. The concern here is with the identity of the mother and the threat to the legal definition of motherhood arising from fragmenting genetic, gestational, and social mothers. ${ }^{9}$

Other Western European nations also ban egg donation (although some permit egg sharing, which will be addressed in the section "Concerns about donor recompense within developed nations"), and some countries allow egg donation but have instituted various regulations or expectations which differentially control oocyte donation practices and payment for such donations. ${ }^{10}$ The differential levels of regulation of egg donation across the globe have resulted in a patchwork of practices defining who may donate eggs, to whom can they be donated, and for what purposes. Given the relative ease of international travel and information sharing, the varied national laws and restrictions on reproduction through egg donation underpin a system in which individuals of adequate economic means travel to regions where they can access the technologies necessary to meet their goals of family development. ${ }^{9,11-13}$

\section{Legal inconsistencies encourage cross-national travel for treatment}

Outright bans on reproduction using egg donation or legal restrictions on the process that control who has access to the technology or which complicate the process and increase wait times for treatment encourage transnational travel for those seeking treatment. Reproductive biocrossings, as these travels are labeled by Gupta, ${ }^{14}$ are most likely to occur when access to reproductive care is restricted in one's home country. Travelers cite such motivating factors as limitations on the legality of (anonymous) egg donation and ART for single women, unmarried couples, or same sex couples, age limitations on accessing fertility treatments, costs associated with egg donation, shortage of donor eggs or shortage of donors with specific characteristics, and extensive delays in access to in vitro fertilization (IVF) treatment with donor eggs. ${ }^{12,14,15}$

Reproductive travel to circumvent legal restrictions on access to ART using egg donation may involve travel to areas of equal or higher economic conditions. Few jurisdictions have collected verifiable data on cross-national travel for fertility care, yet a survey by the International Committee Monitoring Assisted Reproductive Technologies in 2006 suggested that many European patients travel to Spain for fertility care, including sperm and oocyte donation. ${ }^{12}$ Travel to such destinations as the US, Latin America, South America, Japan, Egypt, India, Russia, and Eastern Europe has been reported. However, when the costs of treatment are among the motivating factors, travel is often by potential recipients of more solid economic status to less affluent countries where donor payment is legal and cost is lower than in their home countries, raising concern of economic coercion of "voluntary" egg donors and other social justice issues. ${ }^{14,15}$ Gupta notes that in India, where egg donation 
is loosely regulated, prospective donors can earn more by providing eggs for third party reproduction than in other lines of work in the local economy, making financial gain the primary incentive for donating eggs. ${ }^{14}$ This is in spite of that fact that typical payment of donors in India is the paltry equivalent of $\$ 120$ per cycle, encouraging the exploitation of women in lower resourced settings in the global reproductive marketplace. ${ }^{14,16}$ However, it has also been noted that women's agency in participating in egg donation can only be understood as a product of larger structural inequalities in which getting paid for providing eggs may in fact be a better economic pathway for women than traditional forms of work. ${ }^{14,15}$ Gupta characterizes these circumstances as a manifestation of gender injustice and "social (distributive) injustice in India" for which the state should be held accountable through banning the global egg trade. ${ }^{14}$ Gupta is not alone in this concern. Other scholars have argued that paying women who donate in such cross-national arrangements based on their local currency values and national regulatory contexts (or lack thereof) is potentially exploitative, as it provokes questions about gender, race, class, and global justice implications of the value of women's eggs in lower and higher resourced contexts. ${ }^{17-20}$

There is little legal or regulatory oversight of transnational oocyte donation outside of Europe, where tracking cells involved in cross-border oocyte donation is regulated under the European Union Tissues and Cells Directive. ${ }^{19}$ Trafficking outside these boundaries has the potential to increase the vulnerability of women recruited to participate in oocyte donation. ${ }^{19}$ Even in national contexts where financial compensation and reward for oocyte donors are prohibited, there is evidence to suggest that transnational trade in oocytes involves payment to donors - be they in the form of recompense, reward, or purchase ${ }^{4}-$ which may be in violation of domestic law. ${ }^{21}$

\section{Morality of payment}

The ethical debate on paying women for their gametes has hinged on whether oocytes can be conceptualized as something that has market value or whether they inhabit a sacred category of human life that cannot or should not be commodified. ${ }^{22}$ Arguments in the latter realm borrow from the ethical positions laid out in response to purchase of organs such as kidneys. ${ }^{23}$ But they go one step further. Some who believe that no trade in oocytes can be considered ethical argue that gametes are the building blocks from which unique human beings are created, and, as such, they should not be purchased or commodified. To do so cheapens the meaning of human reproduction and family building. As Cynthia Cohen argued:

"Purchasers receive a product of your body that can be manipulated to create, not just a generic child, but a particular child with certain distinctive features and characteristics derived from you [...]. The derivative dignity of human gametes is being denied as they come to command varying prices in the marketplace, depending on the value of certain features of their progenitors. In effect, this amounts to the purchase of children. It also involves purchasing parenthood, for it exchanges for money that special relation between the gamete provider and the child who results from his or her gamete that providers recognize cannot be denied." 24

Taken to its logical end point, many argue that the only truly ethical form of egg donation is one in which the women providing the eggs receive absolutely no payment whatsoever. Many studies demonstrate that former eggs donors most commonly cite altruist motives for their donations. ${ }^{25-27}$ The idea that they have provided a potential means by which a women or couple can have a child may be reward in and of itself.

However, others argue that a process which prohibits payment for egg donors and provides no regulatory oversight of ART practices actually may leave potential donors more vulnerable than ones which define appropriate payment at a level that supports the adequate availability of oocytes. For instance, Jones and Nisker express concerns that prohibition of aboveboard payment for egg donation would encourage the development of black markets for egg procurement which could leave women unaware of the risks entailed in the process, while paying far less than would be offered in a more open situation. ${ }^{28}$

It is in response to arguments that payment to donors commodifies their eggs and calls for regulatory oversight that those active in the fertility industry emphasize that they are not in the business of purchasing eggs. They prefer use of the term donation to characterize gamete provision. This position is echoed in the nearly universal pronouncement that any recompense for egg donation is designed to meet only the financial and nonfinancial costs accrued by the provider, specifically for her lost wages, transportation costs, discomfort, time, inconvenience, and effort and is unrelated to the number of oocytes retrieved for donation, as purchase of individual oocytes would be in violation of laws against the sale of certain bodily products such as organs. ${ }^{5,23}$ This rationale for recompense of oocyte donors 
leaves several questions unanswered: Should recompense be only for verifiable direct costs to the donor such as lost wages or travel expenses that can be reimbursed? Does the donor need to verify missed work and provide receipts for travel? Or should recompense also include compensation for less objectively verifiable cost such as physical discomfort and inconvenience? Finally, how are potential, but as yet unidentifiable, physical and psychological risks that may not become apparent until many years later to be taken into account in compensation schemes?

One can argue that failure to pay egg donors is disrespectful and devalues the significance of their physical contribution and the potential impact on their health. ${ }^{5}$ While egg donation has been a major feature in fertility treatment for a long time, clear data on the long-term risks associated with ovarian stimulation and egg harvesting in healthy and fertile young women do not exist. ${ }^{25}$ The practice of anonymous egg donation - which has been the norm in the largest egg donation markets - need not preclude rigorous monitoring of aftereffects of the process, yet in most jurisdictions longterm tracking of donors has been nonexistent. ${ }^{25}$ If we are to allow or even encourage young women to donate eggs, perhaps our most ethical option is to pay them well for their services, compensating them for more than direct financial losses and immediate nonfinancial losses.

One might expect that shifting towards a system of identifiable donation might provide some insight into the effects of levels of compensation on donor supply and satisfaction. In recent years, some jurisdictions, eg, the UK and The Netherlands, have ruled that children resulting from the use of these technologies have a right to know the identity of their gamete donor(s). Many theorized that such a requirement would result in a marked decline in willing donors. ${ }^{29}$ Surveys of previous anonymous egg donors indicated that a good proportion would not donate if they were required to be identified..$^{29}$ Introduction of nonanonymity regulations corresponded to declines in donor numbers in both the UK and The Netherlands but the declines appeared to be transient. ${ }^{30}$ Not long after the rule requiring donor identifiability went into effect in the UK, donor recompense levels were increased, in part to counter the effect of the identification rule, making it difficult to understand either the effects of donor anonymity (or lack thereof) or donor recompense on donor supply.

It is clear, however, that donors and children resulting from their donation each have justifiable rights (eg, to health, to security from future demands by unknown offspring, to knowledge of one's genetic and cultural heritage), and these rights need to be kept in balance. Part of this balance may be reflected in donor payment rates. To the extent that a society wishes to accommodate the family building desires of infertile individuals and couples by making egg donation possible, the rights of all parties involved will have be to weighed carefully. Prohibiting anonymity may eliminate some potential donors from the process completely while others may assume any added long-term risk as long as their reward (tangible or intangible) balances the added concern.

\section{Concerns about donor recompense within developed nations}

Many nations and localized professional organizations have grappled with the question of appropriate recompense for egg donors. Some support financial compensation of donors and/or benefits in kind, including reduced treatment fees, for IVF patients who donate supernumerary oocytes and sperm to other fertility patients (egg and sperm sharing). In some jurisdictions, the state subsidizes fertility treatment involving donated oocytes. ${ }^{17,31,32}$ Similar to lifting donor anonymity, limitations on donor compensation has been shown to have a deleterious effect on the availability of donor gametes. ${ }^{29}$ Even reduction of the monetary value of gamete sharing, as occurs when the state covers the cost of IVF cycles, dramatically reduces oocyte sharing. ${ }^{33}$ This has resulted in localized attempts to regulate compensation of donors in a manner that supports adequate levels of donations without seeming to compel donation without regard to potential physical risks.

Underpinning most regulation is the expectation that without the prospect of reimbursement and compensation, women are less likely to consider enduring the physical, emotional, and financial costs (such as from lost wages or transportation fees) to participate in the egg donation process. ${ }^{31}$ Recent modifications of recompense practices have been enacted in response to sparse egg supply in some locales. For instance, in 2012, Britain's Human Fertilisation and Embryology Authority (HFEA) raised the maximum donation cycle from $£ 250$ ( $\$ 425$ in 2014 US dollars) and up for reimbursement of actual expenses incurred by the egg donor to a flat rate of $£ 750$ ( $\$ 1,276$ US). ${ }^{32,34}$ The increase in the reimbursement rate is not as dramatic as it appears since the earlier reimbursement allowed for coverage of all expenses donors incurred above that base. The new flat rate nevertheless is presented as being more respectful of the donor's contribution by more adequately meeting the costs she endures without having the pressure and degradation of haggling over receipts for expenses. ${ }^{34}$ In Spain, donors receive a lump sum payment of $€ 900$ ( $~ \$ 1,227$ US) while 
France limits payments to donors to reimbursing travel costs only. ${ }^{34}$ In 2010, Israel moved from a system allowing only egg sharing by women undergoing fertility-related IVF treatments, to one permitting donation by any woman between the ages of 21 and 35 for a payment set by the Knesset Labor, Welfare and Health Committee. ${ }^{35}$ Originally the pay rate was set at NIS 9,000 ( $\$ 2,625$ US), but this level of payment did not result in substantially increasing egg donations as desired; in July, 2013, The Jerusalem Post reported that only seven Israeli women donated eggs during the previous year. ${ }^{36}$ While there are no data to indicate that limited payment was the basis for this dearth of Israeli egg donors, in 2013 the Knesset committee raised the approved rate of payment to NIS 20,000 ( $\sim \$ 5,787$ US) in a further attempt to encourage Israeli women to donate oocytes. ${ }^{36}$

\section{Factors considered in determining acceptable payment for egg donation}

Debates about the level of payment for oocyte donors and oocyte sharing arrangements have focused on the motivations of populations whose oocytes are sought in these arrangements, and have suggested that women who are facing financial insecurity or poverty may be more easily induced to donate or share oocytes for financial compensation or reduced IVF fees. ${ }^{3,28,37,38}$ Ethics and psychological research on the matter is divided on whether economically-challenged women are potentially more vulnerable to accepting risks in the face of higher payment for donating their oocytes. ${ }^{7,38}$ Nations and professional groups have worked to set payment guidelines which maximize altruistic motivations of donors while minimizing the temptation to take excessive risks for financial gain.

Agency attitudes toward assumed donor motivations are reflected in the HFEA recommendation that egg sharers may receive greater payment than egg donors. Apparently, HFEA has concluded that the motivations of egg sharers are more valued than those of egg donors. Egg sharers undergo the risks of the egg harvesting procedure for their own reproductive benefit. Unless there is an intentional modification of treatment to increase the number of oocytes harvested, the decision to share unused eggs should not add substantial physical risk. Egg donors, on the other hand, would not be undertaking any risk if not for their decision to assist others in their reproductive quest. "The argument here is that the financial rewards or 'inducements' for egg donors are liable to reduce significantly the quality of their consents, whereas this will generally be less of a problem for egg sharers." 34
The HFEA position suggests that the motives of eggs sharers - to produce a child for themselves - are more valiant than that of egg donors - to help another produce a child. This approach is curious but, clearly, while the monetary benefit of the hidden payment to egg sharers may be greater, it lacks the harsh reality of cash payment made to egg donors. That alone may make it more acceptable. However, Wilkinson has argued that it is unfair to reward oocyte sharers more generously than oocyte donors because the policy promotes inconsistent treatment of oocyte providers on the basis of why they are donating. ${ }^{34}$

In the US context, a federalist system of regulation of oocyte donation is in place whereby individual states within the nation can establish their own laws regarding payment for donors. The existing federal regulation on clinic reporting requirements does not address donor payment. ${ }^{39}$ Statebased legislation pertaining to oocyte donation has primarily focused on establishing parental rights of the recipient mother, terminating the parental rights of the donor, releasing donor identity to donor offspring, and oversight of ethical clinical practice involving oocyte donation. ${ }^{23}$ However, there are illustrative examples of how payment has factored into the development of state-level legislation. For instance, the state of Louisiana has banned the sale of oocytes, though it allows compensation for donors' time and inconvenience; Indiana caps compensation for oocyte donors at $\$ 3,000$ per donation cycle in addition to reimbursable expenses; the state of Florida only permits "reasonable" compensation related to oocyte donation; and Virginia's law excludes oocytes from the list of body parts that cannot be purchased or sold. ${ }^{10,39}$ These statutes fail to define what constitutes a "reasonable" level of compensation. In the domain of oocyte donation for research purposes, California has explicitly banned compensation for donation while New York has permitted compensation for research donation at the same rate as donation for reproduction. ${ }^{10,40}$

In the absence of federal regulation, the practice of compensating oocyte donors for their discomfort, time, and effort in the US has emerged organically through clinical practice and later through the development of professional practice guidelines, which have no formal regulatory power. The American Society for Reproductive Medicine (ASRM) has provided its members with professional guidelines on egg donor compensation based on precedents set in the clinical practice of sperm donation and market value as established by peer institutions. ${ }^{18,41}$ Current ASRM guidelines suggest that compensation for oocyte donors is permissible in the $\$ 5,000-\$ 10,000$ range, which is still a wide differential. 
The Ethics Committee of ASRM argues that to pay donors more than $\$ 10,000$ per donation cycle poses the risk that prospective donors would be unduly motivated to discount the risks of participating in oocyte donation and to underreport their personal medical histories for financial reward. ${ }^{5,18,42}$ The recommendation of $\$ 5,000$ as reasonable compensation for a single oocyte donation cycle was developed by comparison to compensation rates to sperm donors $(\$ 60-\$ 75$ per hour in 2000) multiplied by the approximate number of hours required for participation in clinic visits for oocyte donation (estimated to be around 56 hours) with some additional compensation for the more substantial nonfinancial risks and discomforts of undergoing oocyte donation than sperm donation. ${ }^{5,42}$

Recently the ASRM professional guidelines have become the subject of a lawsuit filed by an oocyte donor who claims that compensation guidelines unfairly burden prospective donors by fixing the prices that they can command for donating their oocytes. ${ }^{42}$ Legal scholar Kimberly Krawiec has argued that the ASRM justification for limiting donor compensation is at odds with economic theory due to "product scarcity, which deprives fertility treatment patients of the full range and number of oocytes that would be available to them in a free market." ${ }^{\prime 2}$ Since the compensation for donors is capped through professional society guidelines, patients willing to pay more to ensure they can achieve their reproductive goals may be trapped into paying additional fees directly to fertility clinics. She argues that the justifications ASRM has given for setting the current limit on compensation for oocyte donation are inadequate and provide insufficient explanation as to why this constitutes reasonable compensation. It is unclear how the figure proposed by the professional society protects against risks that might arise in a free market, or how undue inducement or coercion can be understood without specific consideration of a donor's financial need.

\section{Impact of donor payment on recipients' access to treatment}

Economic research has demonstrated that costs to patients plays an important role in determining levels of uptake of ART and equity of access to treatment. ${ }^{43}$ In resource-rich countries, the availability of public funding and insurance mandates to cover costs associated with ART can significantly lower the economic burden of ART for patients, without dramatically impacting the overall costs to the payer. ${ }^{43}$ Though the World Health Organization recognizes infertility as a public health problem and recommends public assistance for treatment, this becomes more challenging in lower-resource settings where basic health care needs remain unmet. In these settings public and third party insurance funding for ART is not prioritized, but nonprofit organizations have stepped in to try to provide some support. ${ }^{43}$

In the UK some have argued that when public funding for egg donation is unavailable, it is more equitable to support "treatment-in-kind" through egg sharing arrangements (where recipients subsidize some of the costs of another patient's IVF for donating some of her oocytes) over turning people away for being unable to pay for ART treatment. ${ }^{44,45}$ But some US-based clinicians and professional societies have argued that in the current context in which fertility treatment is typically paid for by patients rather than covered by insurance, increasing donor compensation will inevitably increase the costs of treatment to recipients, thereby pushing this fertility treatment option further out of the financial reach of some individuals and couples.,37,46,47 McGrath and Sauer explain that the costs of an oocyte donation cycle - which currently hover around $\$ 25,000$ - have increased rapidly since the 1990s due to increased compensation for donors, screening and testing of prospective donors, and regulatory requirements. ${ }^{47}$ Other ethicists have argued that in the absence of public funding for assisted reproduction, which remains the case in most national contexts, access to donor oocytes should be conceptualized as a health equity issue, especially for low-income women and cancer survivors experiencing oocyte depletion. ${ }^{28}$

The use of public or private insurance to cover treatment for infertility remains controversial. Only 32 nations reported insurance coverage for ART for the International Federation of Fertility Societies Surveillance 2010 report. ${ }^{48}$ All place limits on access to such support. Israel rates as among the most generous in its support policy, providing benefits until the woman has given birth to two children. Other nations restricted the amount paid per cycle, the number of cycles supported, and/or the age or medical conditions of the women receiving support. In the US, where insurance is private, only 15 states mandate that infertility care be covered by insurance policies, and the level of coverage varies by state. ${ }^{49}$ Johnston and Gusmano argue that third party payment for ART may reduce public health costs overall by reducing the incentive for ART users to opt for the transfer of multiple embryos in hope of meeting their reproductive goal in as few cycles as possible. ${ }^{50}$ These scholars make the case that payment for IVF, while expensive, is less than that of payment for the potentially life-long impairments which are much more common with births of multiples. A similar argument can be made for government and private insurance covering the 
cost of egg donation if they are to cover ART at all in that success rates for ART using donated eggs may exceed those achieved using the woman's own eggs when specific medical or age factors are present. However, this specific issue has yet to be debated in the realm of public policy. ${ }^{43}$ Regardless of who pays for the treatment, determination of a just donor payment should balance the rights of donors to adequate compensation and the economic costs to individuals or entities bearing the treatment costs.

\section{Influence of market conditions and donor characteristics on payment for egg donation}

Further complicating matters of justice, there is some evidence that, even under current limitations, market conditions do affect donor payment rates. According to a 2006 survey of typical and maximum payment rates self-reported by Society for Assisted Reproductive Technology (SART) medical programs, donor payment rates are inconsistent across the US. ${ }^{51}$ The SART survey noted geographic differences in both the typical and the maximum donor payment by clinics with the highest average standard rates paid in the West $(\$ 4,890)$ and East/Northeast $(\$ 4,217)$ and lowest in the Northwest $(\$ 2,900)$. The authors suggest that these differences might be dependent on differential costs of living in these geographic regions. The same survey found that many clinics reported a maximum reward well above what they declared to be their standard compensation rate. The basis for above standard payment is unclear; $80 \%$ of the clinics indicated that they have a standard rate of compensation and that payment rates did not correspond to such donor characteristics as number of prior donations, prior fertility history, or ethnicity, but none offered an explanation for the above-standard payments to some donors.

There is also evidence that some US clinics advertise financial rewards at rates above the ASRM compensation guidelines to recruit prospective oocyte donors with specific traits. ${ }^{52,53}$ In other words, the free market economy does seem to be at work in third party reproduction in the US, at least in advertisements designed to attract egg donors. The reward offered for egg donation varies with the quality of the product and its scarcity. Highly sought after donor characteristics include elite university education, high college entrance exam test scores, physical beauty, ability in sports, scholastics, or music, specific ethnicities, and prior success as a oocyte donor; advertisements seeking donors with these traits promise higher rates of reward. ${ }^{18,52,53}$ Keehn et al report that clinics and agencies that mention donor traits on their websites advertise higher payment rates for women who have had previous success as a donor or who embody specific levels of educational attainment and standardized test scores, specific ethnicities, creative or athletic ability, and physical beauty. ${ }^{53}$ The authors acknowledge that these types of advertisements are more likely to be managed by donor agencies and by clinics that are not ASRM/SART-approved. But those same clinics and agencies are likely to mention the ASRM guidelines for reasonable compensation within the $\$ 5,000-\$ 10,000$ range in their advertisements. Such advertisements are less likely to mention risks associated with donation than their ASRM/SART-approved counterparts, however. So while these agencies and clinics may offer rates of reward that are out of compliance with the professional society guidelines for donor compensation, they seem to have awareness of the terms of these guidelines. While it is difficult to know whether some donors actually receive the higher reward as advertised, variability in advertised payment rates in the US may reflect either the lack of regulatory muscle of compensation guidelines issued by professional societies, the unwillingness by the industry to self-regulate in this realm, or both. ${ }^{42,52}$

Ethicists have raised concerns about variable reward rates for oocyte donors on numerous scales. Some have argued that higher reward to donors with specific traits has the potential to promote the intentional selection of specific traits that are highly prized in society by those who can afford the higher costs. This practice may also promote misconceptions about genetic inheritance and treads dangerously towards positive eugenics and the creation of a designer baby market. ${ }^{37,52,53}$ Critics of this stance have argued that mate selection in traditional reproduction is no different from trait selection in third party reproduction, and should not be cause for ethical concern, ${ }^{7}$ and that higher rates of reward to donors of specific ethnicities who are less likely to donate may allow recipients to have a child that resembles them. ${ }^{53}$ However, others have argued that there is something inherently unfair about rewarding donors at differential rates based on individual characteristics such as where one attended college, which cannot be definitively linked to traits that are genetically inherited. ${ }^{18}$ Catherine Waldby raises a similar concern in her projection that if compensation for research donors becomes more accepted, paying research donors and reproductive donors at different rates would also promote inconsistency and potentially devalue the eggs of some donors over others. ${ }^{20,54}$

Assuming that egg donor reimbursement and compensation is for the financial and nonfinancial costs donors actually 
incur, one would expect it to be correlated with the cost of living at the donation locale and/or the occupation of the donor (assuming lost work time due to the donation). This fits with the geographic differences in recompense rates found through the SART survey. ${ }^{51}$ Aaron Levine's work suggests that other factors are involved in fee setting, however. ${ }^{52} \mathrm{His}$ analysis of 111 egg donor recruitment ads placed in 63 different university or college newspapers from across the US showed that variables clearly not related to the individual donor's costs were highly correlated with the amount of compensation offered in advertisements. Geographic demand for eggs (measured as number of IVF cycles per million residents in the state) was correlated with significantly higher payment rates offered in college newspaper advertisements. While the demand side of the economic equation can be seen as a neutral economic influence, the same rationale cannot be offered for other reward differentials. Levine's analysis indicated that "an increase of one hundred Scholastic Aptitude Test (SAT) points in the score of a typical incoming student increased the compensation offered to oocyte donors at the college or university by $\$ 2,350 . "{ }^{52}$ Indeed, offers of $\$ 20,000$ (twice the ASRM recommended limit) were found only in newspapers of the colleges and universities with the highest incoming student SAT scores. It is clear that at least some attempt is being made to recruit donors based on individual characteristics such as presumed intelligence (as measured by SAT score of students at a given educational institution). Reward differentials related to SAT score of school is seen in advertisements placed by donor agencies, particularly ads placed by donor agencies in regard to a specific couple and is not a significant factor in advertisements placed by fertility clinics.

\section{Looking forward: ethical and legal aspects of payment for cryopreserved donated oocytes}

Until recently, egg donation was accomplished through direct supply of freshly collected eggs to a specific recipient. Even with a relatively direct contractual agreement between donor and recipient, ethical controversies have arisen related to ownership of embryos generated from a given donation but stored for later use. ${ }^{10}$ Questions have arisen over whether the egg donor should have any input into the disposition of embryos produced from her eggs that were not being specifically used for reproduction by the assumed recipient. ${ }^{55}$

The application of new cryopreservation methods in assisted reproduction raises the potential for new ethical and regulatory challenges pertaining to oocyte donation. Oocyte cryopreservation techniques involving vitrification allow for the possibility of freezing and storing oocytes for later use, similar to the decades-long practice of sperm banking. The experimental label on oocyte cryopreservation was lifted by the ASRM and European Society for Human Reproduction and Embryology in 2012. ${ }^{56}$ Egg donors can now provide their oocytes to be stored for later use by a yet-to-be determined recipient. ${ }^{56}$ Though this process need not change payment schemes for donors, it can affect donor control over the recipients of her eggs and increase her uncertainty of the outcome(s) of her donation(s). The fact that donors may have reduced or even no knowledge of the reproductive struggles of the recipients of their eggs may influence the balance between donors' altruistic and financial motivations. Exactly how this will play out in terms of donors' expectations of payment remains to be seen.

Costs to recipients using cryopreserved eggs will clearly be affected if cryopreservation becomes the norm. Swain suggests that clinics should be prepared to allocate costs of storage, laboratory fees, and medical services to recipients. ${ }^{23}$ She further cautions that banked oocytes could be utilized to assist more than one recipient or couple, and that these costs should be appropriated across these recipient groups. Others have suggested that oocyte banking may change the ways in which legal agreements are developed between donors and recipients, and little is known yet about whether oocyte banks would be regulated similarly to or differently from sperm banks. ${ }^{10,47}$ In light of an active history of case law in assisted reproduction, legal scholars advocate for the establishment of legal agreements between donors and recipients - where each party has their own legal counsel - to address the financial terms of the arrangement (among other issues) to reduce potential vulnerabilities for all parties involved. ${ }^{10}$

\section{Conclusion}

The past three decades have seen thousands of children born throughout the world using eggs collected from donors, sometimes known, sometimes anonymous, sometimes remunerated, sometimes not. The success of the procedure in assisting reproduction for those desiring children cannot be denied. But the ethical and legal challenges of third party reproduction using donor eggs have only become more complicated over time. Consensus regarding the use of donor oocytes and the payment such donors receive is not likely to occur on a local let alone an international level. It is critical, however, that we continue to monitor the procedures related to the recruitment, treatment, reimbursement, compensation, and financial reward of egg donors critically and continuously to 
assure that appropriate safeguards for the health and safety of egg donors (and recipients) are in place, and that they reflect the most current state of our understanding of the physical and psychological consequences of oocyte donation on women's lives.

\section{Disclosure}

The authors report no conflicts of interest in this work.

\section{References}

1. Lutjen P, Trounson A, Leeton J, Findlay J, Wood C, Renou P. The establishment and maintenance of pregnancy using in vitro fertilization and embryo donation in a patient with primary ovarian failure. Nature. 1984;307(5947):174-175.

2. Centers for Disease Control and Prevention, American Society for Reproductive Medicine, Society for Assisted Reproductive Technology. 2011 Assisted Reproductive Technology National Summary Report. Atlanta, GA: US Department of Health and Human Services; 2013. Available from: http://nccd.cdc.gov/DRH_ART/Apps/ NationalSummaryReport.aspx. Accessed May 11, 2014.

3. Klein JU, Sauer MV. Ethics in egg donation: past, present, and future. Semin Reprod Med. 2010;28(4):322-328.

4. Nuffield Council on Bioethics. Human Bodies: Donation for Medicine and Research. 2011. Available from: http://nuffieldbioethics org/wp-content/uploads/2014/07/Donation_full_report.pdf. Accessed September 9, 2014.

5. Ethics Committee of the American Society for Reproductive Medicine. Financial compensation of oocyte donors. Fertil Steril. 2007;88(2):305-309.

6. Daniels K. Donor gametes: anonymous or identified? Best Pract Res Clin Obstet Gynaecol. 2007;21(1):113-128.

7. Robertson JA. Is there an ethical problem here? Hastings Cent Rep. 2010;40(2):3.

8. Inhorn MC, Patrizio P. The global landscape of cross-border reproductive care: twenty key findings for the new millennium. Curr Opin Obstet Gynecol. 2012;24(3):158-163.

9. Bergmann S. Reproductive agency and projects: Germans searching for egg donation in Spain and the Czech Republic. Reprod Biomed Online. 2011;23(5):600-608.

10. Crockin SL, Altman AB. Statutory and case law governing the practice of third-party reproduction. In: Sauer MV, editor. Principles of Oocyte and Embryo Donation. 2nd ed. London: Springer; 2013: 351-368.

11. Inhorn MC, Patrizio P. Rethinking reproductive "tourism" as reproductive "exile". Fertil Steril. 2009;92(3):904-906.

12. Nygren K, Adamson D, Zegers-Hochschild F, de Mouzon J; International Committee Monitoring Assisted Reproductive Technologies. Crossborder fertility care - International Committee Monitoring Assisted Reproductive Technologies global survey: 2006 data and estimates. Fertil Steril. 2010;94(1):e4-e10.

13. France L. Passports, tickets, sunscreen, sperm ... [webpage on the Internet]. The Observer; January 15, 2006. Available from: http://observer. theguardian.com/woman/story/0,16929,1684149,00.html. Accessed June 13, 2014.

14. Gupta JA. Reproductive biocrossings: Indian egg donors and surrogates in the globalized fertility market. Int J Feminist Approaches to Bioethics. 2012;5(1):25-51.

15. Ikemoto LC. Eggs as capital: human egg procurement in the fertility industry and the stem cell research enterprise. Signs. 2009;34(4): 763-781.

16. Crozier G. Protecting cross-border providers of ova and surrogacy services? Global Social Policy. 2010;10(3):299-303.

17. Nahman M. Reverse traffic: intersecting inequalities in human egg donation. Reprod Biomed Online. 2011;23(5):626-633.
18. Steinbock B. Payment for egg donation and surrogacy. Mt Sinai J Med. 2004;71(4):255-265.

19. Heng BC. Ethical issues in transnational "mail order" oocyte donation. Int J Gynaecol Obstet. 2006;95(3):302-304.

20. Waldby C. Oocyte markets: women's reproductive work in embryonic stem cell research. New Genetics and Society. 2008;27(1):19-31.

21. Downie J, Baylis F. Transnational trade in human eggs: law, policy, and (in) action in Canada. J Law Med Ethics. 2013;41(1):224-239.

22. Holland S. Beyond the embryo: a feminist appraisal of the embryonic stem cell debate. In: Holland S, Lebacqz K, Zoloth L, editors. The Human Embryonic Stem Cell Debate: Science, Ethics, and Public Policy. Cambridge, MA: MIT Press; 2001:73-86.

23. Swain ME. Oocyte donation: legal aspects. In: Goldfarb JM, editor. Third-Party Reproduction. New York, NY: Springer; 2014:31-39.

24. Cohen CB. Selling bits and pieces of humans to make babies: The gift of the magi revisited. J Med Philos. 1999;24(3):288-306.

25. Kenney NJ, McGowan ML. Looking back: egg donors' retrospective evaluations of their motivations, expectations, and experiences during their first donation cycle. Fertil Steril. 2010;93(2):455-466.

26. Klock SC, Braverman AM, Rausch DT. Predicting anonymous egg donor satisfaction: a preliminary study. J Womens Health. 1998;7(2):229-237.

27. Lindheim SR, Chase J, Sauer MV. Assessing the influence of payment on motivations of women participating as oocyte donors. Gynecol Obstet Invest. 2001;52(2):89-92.

28. Jones M, Nisker J. Health equity and access to oocyte donation. In: Sauer MV, editor. Principles of Oocyte and Embryo Donation. 2nd ed. London: Springer; 2013:371-382.

29. Craft I, Flyckt S, Heeley G, Layland S, Thornhill A, Kelada E. Will removal of anonymity influence the recruitment of egg donors? A survey of past donors and recipients. Reprod Biomed Online. 2005;10(3):325-329.

30. Human Fertilisation and Embryology Authority. New donor registrations [webpage on the Internet]. London: Human Fertilisation and Embryology Authority; 2013 [updated January 28, 2013]. Available from: http://www.hfea.gov.uk/3411.html. Accessed June 28, 2014.

31. Human Fertilisation and Embryology Authority. Donor compensation, reimbursement and benefits in kind [webpage on the Internet]. London: Human Fertilisation and Embryology Authority; 2013 [updated January 21, 2011]. Available from: http://www.hfea.gov.uk/6177.html. Accessed May 10, 2014.

32. Pattinson SD. The value of bodily material: acquiring and allocating human gametes. Med Law Rev. 2012;20(4):576-603.

33. Pennings G, Devroey P. Subsidized in-vitro fertilization treatment and the effect on the number of egg sharers. Reprod Biomed Online. 2006;13(1):8-10.

34. Wilkinson S. Is the HFEA's policy on compensating egg donors and egg sharers defensible? Med Law Rev. 2013;21(2):173-212.

35. Gruenbaum BF, Pinchover ZS, Lunenfeld E, Jotkowitz A. Ovum donation: examining the new Israeli law. Eur J Obstet Gynecol Reprod Biol. 2011;159(1):40-42.

36. Siegel-Itzkovich J. Ministry increases sum paid to women for donating ova [webpage on the Internet]. The Jerusalem Post. July 16, 2013. Available from: http://www.jpost.com/Health-and-Science/Ministry-increases-sumpaid-to-women-for-donating-ova-319937. Accessed May 2, 2014.

37. Daniels CR, Heidt-Forsythe E. Gendered eugenics and the problematic of free market reproductive technologies: sperm and egg donation in the United States. Signs. 2012;37(3):719-747.

38. Gürtin ZB, Ahuja KK, Golombok S. Egg-sharing, consent and exploitation: examining donors' and recipients' circumstances and retrospective reflections. Reprod Biomed Online. 2012;24(7):698-708.

39. Levine AD. The oversight and practice of oocyte donation in the United States, United Kingdom and Canada. HEC Forum. 2011;23(1):15-30

40. Heidt-Forsythe EA. Reconceiving the State: Morals, Markets, and State Regulation of Assisted Reproductive Technologies [dissertation]. New Brunswick, NJ: Rutgers The State University of New Jersey; 2013. 
41. Robertson JA. Compensation and egg donation for research. Fertil Steril. 2006;86(6):1573-1575.

42. Krawiec KD. Egg-donor price fixing and Kamakahi v American Society for Reproductive Medicine. Virtual Mentor. 2014;16(1):57-62.

43. Chambers GM, Adamson GD, Eijkemans MJ. Acceptable cost for the patient and society. Fertil Steril. 2013;100(2):319-327.

44. Ahuja KK, Mostyn BJ, Simons EG. Egg sharing and egg donation: attitudes of British egg donors and recipients. Hum Reprod. 1997;12(12):2845-2852.

45. Blyth E. Subsidized IVF: the development of 'egg sharing' in the United Kingdom. Hum Reprod. 2002;17(12):3254-3259.

46. Sauer MV. Indecent proposal: $\$ 5,000$ is not "reasonable compensation" for oocyte donors. Fertil Steril. 1999;71(1):7-10.

47. McGrath AJ, Sauer MV. The finances of egg donation. In: Sauer MV, editor. Principles of Oocyte and Embryo Donation. 2nd ed. London: Springer; 2013:231-240.

48. Jones HW, Cooke I, Kempers R, Brinsden P, Saunders D. International Federation of Fertility Societies Surveillance 2010: preface. Fertil Steril. 2011;95(2):491.

49. Omurtag K, Adamson GD. The affordable care act's impact on fertility care. Fertil Steril. 2013;99(3):652-655.

50. Johnston J, Gusmano MK. Why we should all pay for fertility treatment: an argument from ethics and policy. Hastings Cent Rep. 2013;43(2):18-21.
51. Covington SN, Gibbons WE; Society for Assisted Reproductive Technology. What is happening to the price of eggs? Fertil Steril. 2007;87(5):1001-1004.

52. Levine AD. Self-regulation, compensation, and the ethical recruitment of oocyte donors. Hastings Cent Rep. 2010;40(2):25-36.

53. Keehn J, Holwell E, Abdul-Karim R, et al. Recruiting egg donors online: an analysis of in vitro fertilization clinic and agency websites' adherence to American Society for Reproductive Medicine guidelines. Fertil Steril. 2012;98(4):995-1000.

54. Waldby C, Kerridge I, Boulos M, Carroll K. From altruism to monetisation: Australian women's ideas about money, ethics and research eggs. Soc Sci Med. 2013;94:34-42.

55. Kalfoglou AL, Geller G. A follow-up study with oocyte donors exploring their experiences, knowledge, and attitudes about the use of their oocytes and the outcome of the donation. Fertil Steril. 2000;74(4):660-667.

56. Gianaroli L, Racowsky C, Geraedts J, Cedars M, Makrigiannakis A, Lobo RA. Best practices of ASRM and ESHRE: a journey through reproductive medicine. Fertil Steril. 2012;98(6):1380-1394.
Medicolegal and Bioethics

\section{Publish your work in this journal}

Medicolegal and Bioethics is an international, peer-reviewed, open access journal exploring the application of law to medical and drug research and practice and the related ethical and moral considerations. The journal is characterized by the rapid reporting of reviews, case reports, guidelines and consensus statements, original research

\section{Dovepress}

and surveys. The manuscript management system is completely online and includes a very quick and fair peer-review system. Visit http://www.dovepress.com/testimonials.php to read real quotes from published authors. 